\title{
Using Avida-ED for Teaching and Learning About Evolution in Undergraduate Introductory Biology Courses
}

\author{
Elena Bray Speth • Tammy M. Long • \\ Robert T. Pennock • Diane Ebert-May
}

Published online: 15 September 2009

(C) Springer Science + Business Media, LLC 2009

Erratum to: Evo Edu Outreach, Vol. 2, No. 3, September 2009

DOI 10.1007/s12052-009-0154-z

In the original version of this article, Dr. Ebert-May was inadvertently affiliated with Center for Research in College Science Teaching and Learning. The correct affiliations are given below.

The online version of the original article can be found at http://dx.doi. org/10.1007/s12052-009-0154-z

E. Bray Speth $(\bowtie)$

Center for Research in College Science Teaching and Learning,

Michigan State University,

270 Plant Biology,

East Lansing, MI 48824, USA

e-mail: brayelen@msu.edu

T. M. Long

Biological Sciences Program, Michigan State University,

East Lansing, MI 48824, USA

R. T. Pennock

Lyman Briggs College and Departments of Philosophy

and Computer Science, Michigan State University,

East Lansing, MI 48824, USA

D. Ebert-May

Department of Plant Biology, Michigan State University,

East Lansing, MI 48824, USA 